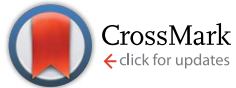

Cite this: RSC Adv., 2017, 7, 11094

Received 8th December 2016 Accepted 3rd February 2017

DOI: 10.1039/c6ra27936h

rsc.li/rsc-advances

\section{Stability and clusterization of hydrogen-vacancy complexes in B2-FeAl: insight from hydrogen embrittlement}

\author{
Guikai Zhang, ${ }^{\text {abc }}$ Guangqi Huang, ${ }^{\mathrm{b}}$ Meijuan Hu, ${ }^{\text {a }}$ Feilong Yang, ${ }^{\mathrm{a}}$ Lang Liu, ${ }^{\mathrm{a}}$ \\ Jürgen Konys*c and Tao Tang*ab
}

Little is known about hydrogen-vacancy interactions and their contributions to hydrogen embrittlement $(\mathrm{HE})$ in iron aluminides. $\mathrm{H}$-induced vacancy formation, stability and clusterization of hydrogen-vacancy complexes $\left(\mathrm{V}_{\mathrm{Fe}} \mathrm{H}_{n}\right)$ in B2-FeAl were studied via density functional theory (DFT) and thermodynamic formalism. The presence of an interstitial $\mathrm{H}$ atom in FeAl forms superabundant Fe-vacancies. The $\mathrm{H}$ atoms are more likely to be trapped around the Fe-vacancies than diffuse from one octahedral interstitial site to another. One Fe-vacancy can trap at most six $\mathrm{H}$ atoms to form $\mathrm{V}_{\mathrm{Fe}} \mathrm{H}_{n}$ complexes with $\mathrm{H}$ atoms occupying the six first-nearest-neighbor (1NN) Oct $2 \mathrm{Fe}-4 \mathrm{Al}$ sites of $\mathrm{V}_{\mathrm{Fe}}$ one by one; the $\mathrm{H}-\mathrm{H}$ distances are 1.920-2.785 $\AA$. The $\mathrm{V}_{\mathrm{Fe}} \mathrm{H}_{6}$ complex is the major complex under ambient conditions and prefers to grow larger by clusterization of $\mathrm{V}_{2 \mathrm{Fe}} \mathrm{H}_{12}$ units along $\langle 100\rangle$ and $\{100\}$ with internal $\mathrm{H}_{2}$ molecules closely associated with the crack along the $\{100\}$ planes. Thus we propose a mechanism of isotropic hydrogenated vacancy-cluster induced $\mathrm{HE}$ : hydrogen addition-induced isotropic $\mathrm{V}_{2 \mathrm{Fe}} \mathrm{H}_{12}\langle 100\rangle$ clusters of line and planar shapes are embryos for the formation of cracks and $\mathrm{H}_{2}$ bubbles. This grows ever bigger as a function of $\mathrm{H}$ concentration and eventually leads to the macroscopic failure observed experimentally.

\section{Introduction}

Iron aluminides have been widely studied as high-temperature structural materials because of their high mechanical strength, excellent corrosion/oxidation resistance and low cost. However, they tend to fail when exposed to a small amount of hydrogen or water due to their susceptibility to hydrogen embrittlement (HE). ${ }^{1-10}$ Thus, the nature, causes, and control of HE of iron aluminides are of particular interest, which is a major concern in many industries including oil and gas, off-shore wind turbines, and hydrogen gas transport.

The HE of iron aluminides has been investigated since the 1980s. ${ }^{1-7}$ The crack in FeAl propagates mainly along the $\{100\}$ plane in air. In contrast, in a vacuum, fracture occurs along $\{111\}$ for stoichiometric $\mathrm{Fe}-\mathrm{Al},\{100\}$ for $\mathrm{Fe}-40 \mathrm{Al}$, and $\mathrm{Fe}-35 \mathrm{Al}{ }^{2,3}$ The ductility of Fe-40Al single-slip-oriented single crystals is lower in air than in a vacuum. ${ }^{5}$ Screw oriented single crystals of $\mathrm{Fe}_{3} \mathrm{Al}$ have considerable ductility in both air and a vacuum, whereas the edge-oriented specimens have little ductility in air. ${ }^{6}$

${ }^{a}$ China Academy of Engineering Physics, Institute of Materials, Jiangyou, 621908, China. E-mail: Tangtao@caep.cn

${ }^{b}$ Science and Technology on Surface Physics and Chemistry Laboratory, Mianyang 621907, China

'Karlsruhe Institute of Technology, Institute for Applied Materials, Hermann-vonHelmholtz-Platz 1, 76344 Eggenstein-Leopoldshafen, Germany. E-mail: Juergen. konys@kit.edu
A sessile $\langle 100\rangle$ edge dislocation on $\{001\}$ may be produced by the interaction of two $a / 2\langle 111\rangle$ edge super-partials. ${ }^{7}$ However, experiments to date are limited to the effect of hydrogen on ductility, crack initiation on $\{100\}$, and fractures along $\{111\}$ and $\{100\}$ planes, etc. These have been further discussed with hydrogen-enhanced decohesion (HEDE), adsorption-induced dislocation emission (AIDE) and hydrogen-enhanced local plasticity (HELP) theories. ${ }^{8-10}$ These studies detail new surface formation, bond weakening, hydrogen-dislocation interaction as well as their consequences on HE. However, the atomic level mechanism underlying the formation of $\langle 100\rangle$ edge dislocations, cracks, and fractures is still unclear, including how these failures occur in a defined environment. It is critical to identify fundamentals and create a suppression strategy while also explaining the mechanism of $\mathrm{HE}$ in iron aluminides.

$\mathrm{V}_{\mathrm{Fe}}$ can enhance hydrogen solubility in iron aluminides. They have a high concentration of vacancies (two-fold higher than that of pure metals and disordered alloys). This increases the influence of hydrogen on the mechanical properties. ${ }^{1}$ Hydrogen-related degradations might depend on hydrogen and vacancy related-defective properties and their evolvements. This could identify the specific vacancy, hydrogen, or complexes that link the edge dislocation, crack and fracture as result of HE. However, no further relevant thermodynamic and kinetic information regarding hydrogen and vacancy related-defects in iron aluminides and their contribution to HE is reported. 
Here, we studied H-induced vacancy formation, vacancy trapping of multiple $\mathrm{H}$, and clusterization of hydrogen-vacancy complexes in B2-FeAl via density functional theory (DFT) and thermodynamics formalism to illustrate the contributions of vacancy-related processes to $\mathrm{HE}$ in iron aluminides and to explain experimental results. We also detail the decisive role of $\mathrm{V}_{\mathrm{Fe}} \mathrm{H}_{n}$ clusters as embryos for the formation of edge dislocations, cracks, and $\mathrm{H}_{2}$ bubbles. This work attempts to bridge the link between the atomic-scale events of hydrogen-vacancy complexes and the experimentally (microscopically) observed HE of iron aluminides.

\section{Computational method and model}

DMol3 in Materials Studio of Accelrys Inc. successfully captures the properties of FeAl. ${ }^{11-16}$ In comparison with local density approximation (LDA) and Perdew, Burke, and Ernzerhof (PBE), the density functions confirm the principal findings for FeAl based on Perdew and Wang (PW91). ${ }^{13,15}$ Thus, we performed the calculations within the PW91-GGA (generalized gradient approximation) using a double numerical quality basis set with polarization functions (DNP) ${ }^{17}$ and a semi-core pseudopotential. ${ }^{18}$ The pseudopotential and the basis set also have been used to study the properties of hydrogen, ${ }^{10,14,19} \mathrm{Fe}$ and $\mathrm{Al} .{ }^{20} \mathrm{All}$ spin polarized calculations utilized a convergence tolerance of energy of $2.7 \times 10^{-6} \mathrm{eV}$, a maximum force of $5.4 \times 10^{-3} \mathrm{eV} \AA^{-1}$, a maximum displacement of $5.0 \times 10^{-4} \AA$, a fixed MonkhorstPack mesh $k$-points of $2 \times 2 \times 2$, a real-space cutoff of $5.3 \AA$ and a thermal smearing of $0.002 \mathrm{au}$. No symmetry constraints were imposed. The lattice and all atoms of the supercell are relaxed fully during the calculations of vacancies and anti-sites. The lattice parameter is fixed with atomic position relaxation during the calculation of H-related defects.

With these parameters, energies of the model have converged. For example, in $\mathrm{H}$ adsorption, we tested different real-space cutoffs $(4.8,5.3$ and $5.8 \AA$ ). The adsorption energy only increases by $0.020 \mathrm{eV}$ as the cutoff varies from 4.8 to $5.3 \AA$. It is $0.028 \mathrm{eV}$ at further increases of the cutoff. Thus, a real-space cutoff of $5.3 \AA$ is sufficient to achieve numerical convergence. It is found that ZPE corrections do not essentially affect the subjects investigated in our work, as shown in ref. 21 , thus the results presented here do not include the ZPE corrections.

We obtain a lattice constant of $a=2.888 \AA$ for B2 type FeAl. This agrees reasonably well with previous DFT-GGA calculations ( $a=2.875-2.910 \AA$ (ref. 11-14, 22 and 23)) as well as experiment data $\left(a=2.916 \AA\right.$ (ref. 24)). The calculated binding energy of $\mathrm{H}_{2}$ is $4.565 \mathrm{eV}$, which is in good agreement with the experimental and other DFT values. ${ }^{23} \mathrm{~A}$ vibrational frequency of $4385.60 \mathrm{~cm}^{-1}$ is calculated for $\mathrm{H}_{2}$-in close agreement with experiment $\left(4401.00 \mathrm{~cm}^{-1}\right)^{25}$

A $4 \times 4 \times 4$ supercell containing 128 atoms was constructed for calculations. This was based on the optimized structural parameters for a perfect B2-type FeAl. To introduce an isolated $\mathrm{Al}(\mathrm{Fe})$ vacancy, an $\mathrm{Al}(\mathrm{Fe})$ atom at the center of the supercell is removed to produce a $0.76 \%$ defect in bulk FeAl. In the case of an antisite, a $\mathrm{Fe}(\mathrm{Al})$ atom is put into the $\mathrm{Al}(\mathrm{Fe})$ vacancy to produce a $0.76 \%$ defect in the bulk. The formation energies of
Table 1 Formation energies of vacancies and anti-sites in B2-FeAl versus values from previous studies

\begin{tabular}{llll}
\hline & & \multicolumn{2}{l}{ Previous results } \\
\cline { 3 - 4 } Defects & This work & Cal. $^{1,26-28}$ & Exp. $^{29}$ \\
\hline $\mathrm{V}_{\mathrm{Fe}}$ & 1.19 & $0.65-1.19$ & $0.9-1.1$ \\
$\mathrm{~V}_{\mathrm{Al}}$ & 1.90 & $1.49-4.00$ & - \\
$\mathrm{Fe}_{\mathrm{Al}}$ & 1.44 & $0.70-1.19$ & - \\
$\mathrm{Al}_{\mathrm{Fe}}$ & 0.67 & $0.67-1.03$ & - \\
\hline
\end{tabular}

vacancy and antisite in B2-FeAl are shown in Table 1 , and compared to previous formation energies. The $\mathrm{V}_{\mathrm{Fe}}$ is more favorable than $\mathrm{V}_{\mathrm{Al}}$, and $\mathrm{Al}_{\mathrm{Fe}}$ has lower site preference energy in agreement with previously predicted results. ${ }^{26-29}$ Therefore, we used $\mathrm{V}_{\mathrm{Fe}}$ for all subsequent calculations.

There are three interstitial sites in B2-FeAl including two octahedral interstitial sites and one tetrahedral interstitial site. Fig. 1a shows that the tetrahedral interstitial site consists of two $\mathrm{Fe}$ atoms and two $\mathrm{Al}$ atoms with bond lengths of $\left(\mathrm{Tet}_{2 \mathrm{Fe}-2 \mathrm{Al}}\right)$. One octahedral interstitial site involves two axial Fe atoms and four equatorial $\mathrm{Al}\left(\mathrm{Oct}_{2 \mathrm{Fe}-4 \mathrm{Al}}\right)$. Another one involves two axial $\mathrm{Al}$ atoms with four equatorial $\mathrm{Fe}\left(\mathrm{Oct}_{2 \mathrm{Al}-4 \mathrm{Fe}}\right)$. In an elementary B2cell, $12 \mathrm{Tet}_{2 \mathrm{Fe}-2 \mathrm{Al}}, 3 \mathrm{Oct}_{2 \mathrm{Fe}-4 \mathrm{Al}}$ and $3 \mathrm{Oct}_{2 \mathrm{Al}-4 \mathrm{Fe}}$ sites can be found. In a pre-existing Fe vacancy in bulk FeAl, two possible interstitial positions are considered (Fig. 1b): (1) $\mathrm{H}$ in the first-nearestneighbor $(1 \mathrm{NN})$ octahedral and tetrahedral interstitial sites of the Fe vacancy including $1 \mathrm{NN}$ Oct $_{2 \mathrm{Fe}-4 \mathrm{Al}}, 1 \mathrm{NN}$ Oct $_{2 \mathrm{Al}-4 \mathrm{Fe}}$ and $1 \mathrm{NN} \mathrm{Tet}{ }_{2 \mathrm{Fe}-2 \mathrm{Al}}$ sites, and (2) the second-nearest-neighbor (2NN) sites including $2 \mathrm{NN} \mathrm{Oct} 2 \mathrm{Fe}-4 \mathrm{Al}$ and $2 \mathrm{NN} \mathrm{Tet}_{2 \mathrm{Fe}-2 \mathrm{Al}}$ sites.

The formation energy of interstitial $\mathrm{H}\left(\mathrm{VH}_{n}\right.$ complex) in FeAl host is defined as

$$
E^{\mathrm{f}}(\mathrm{H})=E(n \mathrm{H})-E(\text { bulk })-\frac{n}{2} E\left(\mathrm{H}_{2}\right),
$$

where $E(n \mathrm{H})$ are the energies of the supercell with $n \mathrm{H}$ atoms $(n$ $\mathrm{H}$ atoms in a vacancy), $E$ (bulk) is the energy of the supercell for perfect host lattice (perfect host lattice with a vacancy), and $E\left(\mathrm{H}_{2}\right)$ is the energy of a gas-phase $\mathrm{H}_{2}$ molecule in vacuum.

The formation energy of a Fe vacancy surrounding one $\mathrm{H}$ interstitial atom is defined as

$$
E^{\mathrm{f}}(V)=E\left(\mathrm{H}_{\mathrm{OIS}}, \mathrm{V}\right)-E\left(\mathrm{H}_{\mathrm{OIS}}\right)+E(\mathrm{Fe}),
$$

where $E\left(\mathrm{H}_{\mathrm{OIS}}, \mathrm{V}\right)$ is the energy of the supercell with a vacancy and an interstitial $\mathrm{H}, E\left(\mathrm{H}_{\mathrm{OIS}}\right)$ is the energies of the supercell without vacancy but with an interstitial $\mathrm{H}$ atom, and $E(\mathrm{Fe})$ is the energy of a Fe atom in bulk phase.

The hydrogen-trapping binding energy of $\mathrm{VH}_{n}$ complexs are defined as the energy gain by trapping an interstitial hydrogen atom into a vacancy site to form $\mathrm{VH}_{n}$ complexes. It has been defined as ${ }^{30}$

$$
E^{\text {trap }}(n \mathrm{H})=[E(n-1 \mathrm{H}, \mathrm{V})+E(\mathrm{~V})]-\left[E(n \mathrm{H}, \mathrm{V})+E\left(\mathrm{H}_{\mathrm{OIS}}, \mathrm{V}\right)\right],
$$

where $E(n \mathrm{H}, \mathrm{V})$ or $E(n-1 \mathrm{H}, \mathrm{V})$ is the energy of the supercell with one vacancy, $n$ or $n-1 \mathrm{H}$ atoms, and $E(\mathrm{~V})$ is the energy of the 
(a)

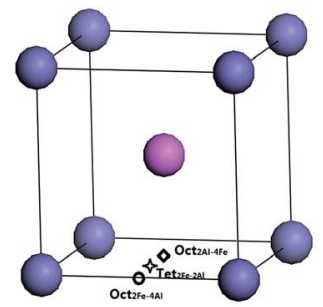

(b)

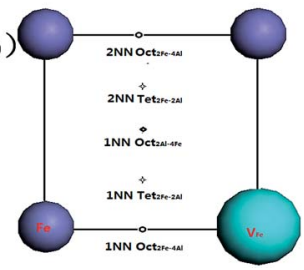

Fig. 1 Schematic view of the octahedral and tetrahedral interstitial sites (a) and possible absorption sites of hydrogen adjacent to $\mathrm{V}_{\mathrm{Fe}}$ in B2-FeAl (b). The navy blue, pink, and light blue balls denote Fe atom, Al atom and Fe vacancy, respectively.

supercell with one vacancy. By definition, positive energy indicates exothermic process.

Migration barriers for point defects are calculated by complete linear synchronous transit/quadratic synchronous transit (LST/QST) method using eleven images. The frequencies are calculated at all critical points identified on the potential energy surface to identify minima and transition states.

\section{Results and discussion}

\subsection{Interstitial $\mathrm{H}$-induced $\mathrm{V}_{\mathrm{Fe}}$ formation}

We first investigated the positions for an individual $\mathrm{H}$ atom interstitial in perfect FeAl bulk to discuss the effect of interstitial $\mathrm{H}$ atom on vacancy formation.

We first investigated the positions for an interstitial $\mathrm{H}$ atom in perfect FeAl bulk. As shown in Fig. 1, the interstitial $\mathrm{H}$ at the $\mathrm{Oct}_{2 \mathrm{Al}-}$ $4 \mathrm{Fe}$ site is unstable, whereas the $\mathrm{Oct}_{2 \mathrm{Fe}-4 \mathrm{Al}}$ site for an interstitial $\mathrm{H}$ is energetically more stable than the $\mathrm{Tet}_{2 \mathrm{Fe}-2 \mathrm{Al}}$ site by $0.02-0.03 \mathrm{eV}$. This coincides with previous calculations $0.02 \mathrm{eV}^{23}$ The corresponding formation energy is $0.50 \mathrm{eV}$ for the $\mathrm{H}$ at the $\mathrm{Oct}_{2 \mathrm{Fe}-4 \mathrm{Al}}$ site with a $\mathrm{H}-\mathrm{Fe}$ bond length of $1.56 \AA$. The $\mathrm{H}-\mathrm{Al}$ bond lengths vary from 2.02 to $2.15 \AA$ (Fig. 2). We find two real modes for the $\mathrm{Oct}_{2 \mathrm{Fe}-}$ 4Al hydrogen at $1506.80 \mathrm{~cm}^{-1}$ and $1507.59 \mathrm{~cm}^{-1}$, which show that the hydrogen in the Oct ${ }_{2 \mathrm{Fe}-4 \mathrm{Al}}$ site is at a local energy minima.

We then created a vacancy by removing a lattice Fe atom surrounding the $\mathrm{Oct}_{2 \mathrm{Fe}-4 \mathrm{Al}}$ hydrogen atom. The formation

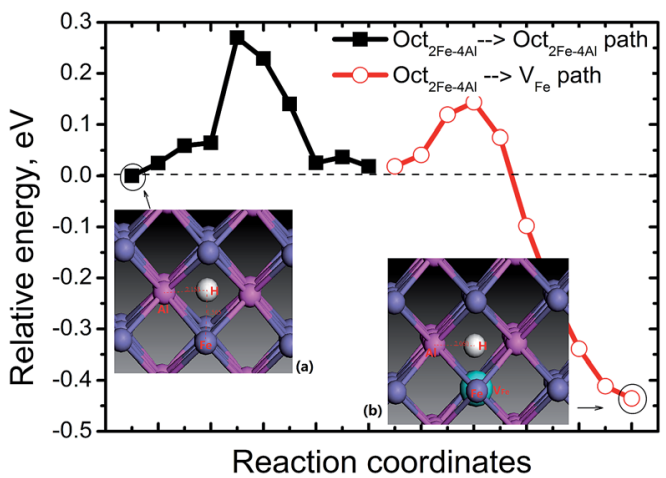

Fig. 2 Energy profiles for $\mathrm{H}$ diffusion in FeAl. The inset figures are the local structure of $\mathrm{H}$ at the Oct $2 \mathrm{Fe}-4 \mathrm{Al}$ site in perfect FeAl (a) and 1NN $\mathrm{OCt}_{2 \mathrm{Fe}-4 \mathrm{Al}}$ site of $\mathrm{V}_{\mathrm{Fe}}(\mathrm{b})$, respectively. The white ball denotes the $\mathrm{H}$ atom. energy of a Fe vacancy near the interstitial $\mathrm{H}$ was $-0.07 \mathrm{eV}-$ significantly lower than that $(1.19 \mathrm{eV})$ of perfect FeAl suggesting that interstitial $\mathrm{H}$ facilitates Fe-vacancy formation near the interstitial in perfect FeAl.

According to Boltzmann statistics, an energy reduction of $0.5 \mathrm{eV}$ leads to a $10^{7}$-fold increase in vacancy density at $300 \mathrm{~K} .^{30}$ The sharply decreased $\mathrm{V}_{\mathrm{Fe}}$ formation energy provides a scenario in which Fe vacancies in FeAl with hydrogen present naturally and are produced in superabundant equilibrium concentration. This agrees with experimental results ${ }^{31}$ and suggests that hydrogen induces superabundant vacancy formation in a number of bcc and fcc metals. ${ }^{32,33}$

\subsection{Single $\mathbf{H}$ trapping in $\mathbf{V}_{\mathrm{Fe}}$}

A pre-existing Fe vacancy in bulk FeAl shows that $\mathrm{H}$ prefers to occupy the $1 \mathrm{NN}$ Oct $_{2 \mathrm{Fe}-4 \mathrm{Al}}$ site $(1.31 \AA$ off-center to the vacancy shown in Fig. 2) with the lowest formation energy of $0.12 \mathrm{eV}$. This is higher than previous calculations. However, the energy difference between the $\mathrm{H}$ at the $1 \mathrm{NN}$ Oct $_{2 \mathrm{Fe}-4 \mathrm{Al}}$ site of $\mathrm{V}_{\mathrm{Fe}}$ and the $\mathrm{H}$ at the $\mathrm{Oct}_{2 \mathrm{Fe}-4 \mathrm{Al}}$ site in perfect $\mathrm{FeAl}$ coincides with previous DFT calculations $(0.38-0.42 \mathrm{eV}){ }^{28}$ This signifies that the $\mathrm{H}$ atoms are trapped around $\mathrm{V}_{\mathrm{Fe}}$ are thermodynamically feasible.

Furthermore, the migration of $\mathrm{H}$ atoms was explored to elucidate how $\mathrm{H}$ is trapped into $\mathrm{V}_{\mathrm{Fe}}$. We considered two cases of $\mathrm{H}$ diffusion: diffusion within $\mathrm{V}_{\mathrm{Fe}}$ (local diffusion) and from an Oct $_{2 \mathrm{Fe}-4 \mathrm{Al}}$ site nearest the $\mathrm{V}_{\mathrm{Fe}}$ (nonlocal diffusion). The local diffusion path does not contribute to the mass $\mathrm{H}$-transport and involves diffusion steps in which hydrogen remains in the $\mathrm{V}_{\mathrm{Fe}}$. Interestingly, we find that the local diffusion is almost a thermoneutral channel and has a barrier of $0.76-1.18 \mathrm{eV}$ indicating that such diffusion cannot occur at room temperature. However, $\mathrm{H}$ migration in the form of non-local diffusion has a barrier of only $0.1 \mathrm{eV}$ along the Oct ${ }_{2 \mathrm{Fe}-4 \mathrm{Al}}$ site $\rightarrow \mathrm{V}_{\mathrm{Fe}}$ path. It is exothermic by $-0.45 \mathrm{eV}$ (Fig. 2). At the saddle point of the Oct $_{2 \mathrm{Fe}-4 \mathrm{Al}}$ site $\rightarrow \mathrm{V}_{\mathrm{Fe}}$ path, there are two real frequencies for the adsorbed $\mathrm{H}$ at 1567.67 and $1718.47 \mathrm{~cm}^{-1}$. There is an imaginary frequency at 734.10 $\mathrm{cm}^{-1}$. At the starting point, the $\mathrm{H}$ has two frequencies at 1566.65 and $1567.46 \mathrm{~cm}^{-1}$. At the end point, $\mathrm{H}$ has two frequencies at 858.44 and $1768.59 \mathrm{~cm}^{-1}$. The reverse path proceeds via a higher energy barrier of $0.55 \mathrm{eV}$. Thus, it is definitely easier for $\mathrm{H}$ to be trapped around the $\mathrm{V}_{\mathrm{Fe}}$ than dissociated from the $\mathrm{V}_{\mathrm{Fe}} \mathrm{H}$ complex.

Separate from the $\mathrm{V}_{\mathrm{Fe}}, \mathrm{H}$ also jumps from one $\mathrm{Oct}_{2 \mathrm{Fe}-4 \mathrm{Al}}$ site to another with the same diffusion barrier for $\mathrm{H}$ in perfect FeAl. In perfect $\mathrm{FeAl}$, the $\mathrm{H}$ atom diffuses and involves $\mathrm{H}$ atom reorientation around the Fe atom from an $\mathrm{Oct}_{2 \mathrm{Fe}-4 \mathrm{Al}}$ site to an adjacent one (path Oct ${ }_{2 \mathrm{Fe}-4 \mathrm{Al}} \rightarrow$ Oct $_{2 \mathrm{Fe}-4 \mathrm{Al}}$ ) by passing through a Fe-Al-Al triangle with a barrier of $0.27 \mathrm{eV}$ (Fig. 2). Real frequencies for adsorbed $\mathrm{H}$ at 1567.67 and $1818.47 \mathrm{~cm}^{-1}$ with one imaginary frequency at $728.10 \mathrm{~cm}^{-1}$ are found at the saddle point of Oct $_{2 \mathrm{Fe}-4 \mathrm{Al}} \rightarrow \mathrm{Oct}_{2 \mathrm{Fe}-4 \mathrm{Al}}$. At the final point, the $\mathrm{H}$ has two frequencies at 1506.46 and $1507.25 \mathrm{~cm}^{-1}$. At the starting point, the $\mathrm{H}$ has two frequencies at 1506.80 and $1507.59 \mathrm{~cm}^{-1}$. Our predicted barrier agrees with the H-diffusion barrier of $0.26 \mathrm{eV}$ in bulk FeAl by DFT calculation, ${ }^{23}$ but these are lower and higher than the experimental barriers of $\mathrm{H}$ diffusivity in $\mathrm{Fe}_{3} \mathrm{Al}$ $(0.42 \mathrm{eV})^{34}$ and Fe-40Al $(0.22 \mathrm{eV}){ }^{35}$ respectively. 
As discussed above, $\mathrm{H}$ trapping around $\mathrm{V}_{\mathrm{Fe}}$ is thermodynamically and kinetically feasible away from the $\mathrm{V}_{\mathrm{Fe}}$. The $\mathrm{H}$ jumps from one Oct $_{2 \mathrm{Fe}-4 \mathrm{Al}}$ site to another with a barrier of $0.27 \mathrm{eV}$. While it is energetically more favorable for $\mathrm{H}$ to be in $\mathrm{V}_{\mathrm{Fe}}$, there is a higher energy barrier exists for Oct $_{2 \mathrm{Fe}-4 \mathrm{Al}} \rightarrow$ $\mathrm{Oct}_{2 \mathrm{Fe}-4 \mathrm{Al}}$ diffusion. In other words, it is possible that there are a number of events involve $\mathrm{H}$ trapping around the $\mathrm{V}_{\mathrm{Fe}}$ at finite temperatures. This forms $\mathrm{V}_{\mathrm{Fe}} \mathrm{H}$ complexes before migration from one octahedral interstitial site to another. The next section will focus on multiple $\mathrm{H}$ trapping in $\mathrm{V}_{\mathrm{Fe}}$.

\subsection{Stability of $\mathrm{V}_{\mathrm{Fe}} \mathrm{H}_{n}$ complexes}

To measure how many $\mathrm{H}$ atoms that can be trapped in a $\mathrm{Fe}$ monovacancy and characterize its corresponding stability, we individually placed several $\mathrm{H}$ atoms (up to 10) into the $\mathrm{V}_{\mathrm{Fe}}$ and relaxed the system to search for optimal positions with every $\mathrm{H}$ atoms.

Inside the $\mathrm{Fe}$ vacancy, the $\mathrm{H}$ atoms first tend to occupy the six $1 \mathrm{NN}$ Oct $_{2 \mathrm{Fe}-4 \mathrm{Al}}$ sites of $\mathrm{V}_{\mathrm{Fe}}$ one by one (less than seven atom). Next, the $\mathrm{V}_{\mathrm{Fe}}$ (seventh $\mathrm{H}$ atom) and the $2 \mathrm{NN} \mathrm{OIS} \mathrm{O}_{2 \mathrm{Fe}-4 \mathrm{Al}}$ site has more than $7 \mathrm{H}$ atoms. For all configurations considered, the $\mathrm{H}-\mathrm{H}$ equilibrium distances remain on the magnitude of 1.920$2.785 \AA$, and the $\mathrm{H}-\mathrm{Fe}$ distances range from 1.538 to $1.568 \AA$ (Fig. 3).

Fig. 4 shows the trapping energy versus the number of $\mathrm{H}$ atoms in a $\mathrm{Fe}$ monovacancy. Clearly, the trapping energy increases with $\mathrm{H}$ incorporation from 0.46 to $0.66 \mathrm{eV}$. For the first $\mathrm{H}$ atom, the trapping energy is $0.46 \mathrm{eV}$. The second trapped $\mathrm{H}$ in the vacancy is energetically $0.07 \mathrm{eV}$ and $0.04 \mathrm{eV}$ higher than the first and third $\mathrm{H}$ atoms, respectively. The fourth, fifth, and sixth $\mathrm{H}$ atoms are more favorable than the second trapped $\mathrm{H}$. With more than six $\mathrm{H}$ atoms, the trapping energy increases sharply and becomes negative, e.g. the seventh trapped $\mathrm{H}$ is energetically unfavorable with a trapping energy of $-1.73 \mathrm{eV}$. The $\mathrm{V}_{\mathrm{Fe}} \mathrm{H}_{6}$ complex has highest trapping energy of $0.66 \mathrm{eV}$. Thus, up to six $\mathrm{H}$ can be trapped in a monovacancy, and the corresponding trapping energies are $0.59-0.66 \mathrm{eV}$ for trapping with 4-6 $\mathrm{H}$ atoms and $0.46-0.53 \mathrm{eV}$ for trapping with 1-3 $\mathrm{H}$ atoms, respectively. The heat of solution for $\mathrm{V}_{\mathrm{Fe}} \mathrm{H}_{n}$, which is the energy compared to $\mathrm{H}_{2}$ molecules in vacuum at ambient conditions,

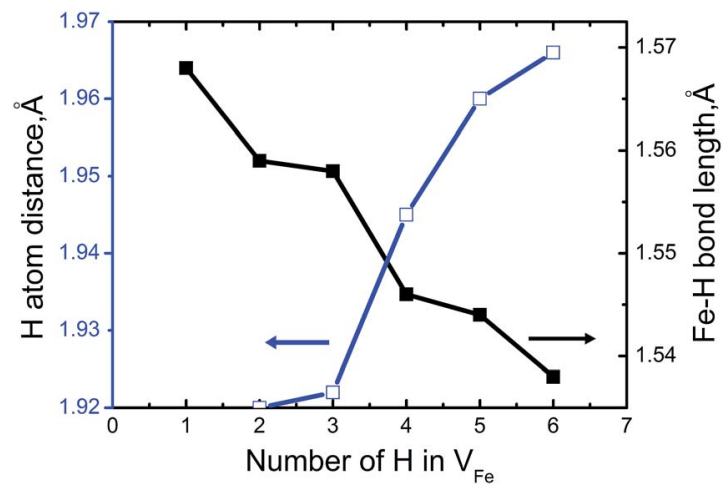

Fig. 3 The minimum distance between hydrogen atoms and $\mathrm{Fe}-\mathrm{H}$ bond length as a function of the number of $\mathrm{H}$ atoms in the $\mathrm{V}_{\mathrm{Fe}} \mathrm{H}_{n}$ complex.

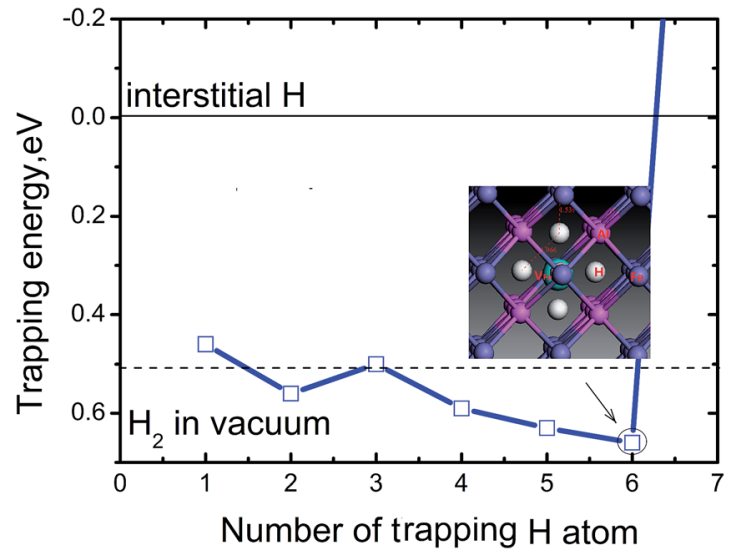

Fig. 4 Trapping energy of $\mathrm{V}_{\mathrm{Fe}} \mathrm{H}_{n}$ complex versus the number of $\mathrm{H}$ atoms $(n)$ trapped in a Fe monovacancy $(n=1-7)$. The dotted line for zero energy is the energy of $\mathrm{H}$ atom at a remote Oct $_{2 \mathrm{Fe}-4 \mathrm{Al}}$ site far away from Fe vacancy, and the dashed line is the energy of $\mathrm{H}_{2}$ molecule in vacuum. The inset figure is the local structure of the $\mathrm{V}_{\mathrm{Fe}} \mathrm{H}_{6}$ complex.

suggests that $\mathrm{V}_{\mathrm{Fe}} \mathrm{H}_{2}, \mathrm{~V}_{\mathrm{Fe}} \mathrm{H}_{4}, \mathrm{~V}_{\mathrm{Fe}} \mathrm{H}_{5}$ and $\mathrm{V}_{\mathrm{Fe}} \mathrm{H}_{6}$ formations are completely exothermic for hydrogen and almost zero for $\mathrm{V}_{\mathrm{Fe}} \mathrm{H}_{3}$. The $\mathrm{VH}$ formations are slightly endothermic. These indicate that $\mathrm{V}_{\mathrm{Fe}} \mathrm{H}_{6}$ is a major complex at ambient conditions due to the largest negative heat of solution for hydrogen.

The electron density difference of the $\mathrm{V}_{\mathrm{Fe}} \mathrm{H}_{6}$ complex is shown in Fig. 5. The electron transfer to the region around the hydrogen atoms from the neighboring Fe clearly shows that the metal-H hybridization occurs between neighboring $\mathrm{Fe}$ atoms and the hydrogen atom (Fig. 5a). In contrast, the $\mathrm{H}$ atom has very little effect on the charge distribution of $\mathrm{Al}$ atoms (Fig. 5b). This coincides with previous DFT calculations. ${ }^{22}$ The electron clouds of the negative $\mathrm{H}$ flatten in $\mathrm{V}_{\mathrm{Fe}}$ indicating the electronelectron repulsion between the hydrogen atoms.

Fig. 3 shows that bond length of $\mathrm{Fe}-\mathrm{H}$ decreases, and the minimum distance between hydrogen atoms increase with increasing trapped hydrogen atoms. This suggests that the metal-H hybridization of $\mathrm{Fe}-\mathrm{H}$ prevails, but the repulsion interaction decreases. Consequently, competition between metal- $\mathrm{H}$ hybridization and coulombic repulsion makes $\mathrm{V}_{\mathrm{Fe}} \mathrm{H}_{6}$ the major complex at ambient conditions. The local structure of the $\mathrm{V}_{\mathrm{Fe}} \mathrm{H}_{6}$ complex is also shown in Fig. 4. The $\mathrm{H}$ atoms clearly occupy the six symmetric $1 \mathrm{NN}$ Oct $_{2 \mathrm{Fe}-4 \mathrm{Al}}$ sites of the $\mathrm{V}_{\mathrm{Fe}}$. Our

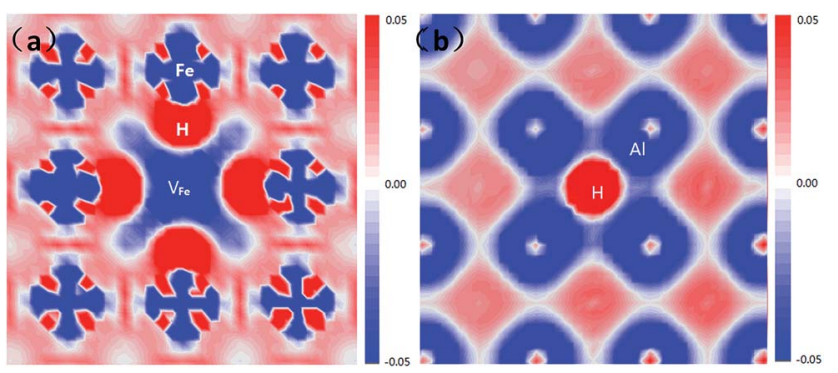

Fig. 5 Electron density difference plots of the $\mathrm{V}_{\mathrm{Fe}} \mathrm{H}_{6}$ complex along with four Fe atoms (a) and four Al atoms (a), respectively. 
results are strikingly and quantitatively similar to those obtained in simulations of bcc and fcc metals. ${ }^{21,36}$

\subsection{Clusterization of $\mathrm{V}_{\mathrm{Fe}} \mathrm{H}_{n}$ complexes}

We next investigated the binding preference of two $\mathrm{V}_{\mathrm{Fe}} \mathrm{H}_{6}$ complexes to examine the energetics of vacancy clusters beyond divacancy. The binding energy $\left(E_{\mathrm{b}}\right)$ of the two $\mathrm{V}_{\mathrm{Fe}} \mathrm{H}_{6}$ complexes is calculated $v i^{30}$

$$
E_{\mathrm{b}}=E(2 \mathrm{H}, 2 \mathrm{~V})+E_{\mathrm{bulk}}-2 E(\mathrm{H}, \mathrm{V})
$$

where $E(2 \mathrm{H}, 2 \mathrm{~V})$ is the energy of the supercell with two vacancies trapped in $12 \mathrm{H}$ atoms, and $E(\mathrm{H}, \mathrm{V})$ is the energy of the supercell with one vacancy trapped in six $\mathrm{H}$ atoms. By definition, positive energy indicates that the binding is energetically favorable. A Fe vacancy occupying a neighbor site of the other along $\langle 111\rangle$, $\langle 110\rangle$ and $\langle 100\rangle$ directions are shown (Fig. 6). The corresponding binding energies are listed in Table 2.

For the hydrogen-free FeAl, the $E_{\mathrm{b}}$ of divacancy along $\langle 111\rangle$, $\langle 110\rangle$ and $\langle 100\rangle$ are calculated to be $-0.001,0.027$, and $-0.012 \mathrm{eV}$, respectively, suggesting that the $\mathrm{Fe}$ vacancies binding is preferred along the $\langle 110\rangle$ directions. This is partially consistent with previous results showing that $\langle 100\rangle$ and $\langle 110\rangle$ divacancy bindings are favorable. ${ }^{27}$ With $\mathrm{H}$ in FeAl, the $E_{\mathrm{b}}$ of the $\mathrm{V}_{2 \mathrm{Fe}} \mathrm{H}_{12}\langle 110\rangle$ formation is lower than that of $\mathrm{V}_{2 \mathrm{Fe}}\langle 110\rangle$, signifying that hydrogen atoms do not facilitate the $\langle 110\rangle$ directionbinding processes. However, versus the negative $E_{\mathrm{b}}$ of $\mathrm{V}_{2 \mathrm{Fe}}\langle 100\rangle$, the positive $E_{\mathrm{b}}$ of the $\mathrm{V}_{2 \mathrm{Fe}} \mathrm{H}_{12}\langle 100\rangle$, and $\mathrm{V}_{2 \mathrm{Fe}} \mathrm{H}_{11}\langle 100\rangle$ (situation of one $\mathrm{H}$ escaping from the unit) suggests that the presence of hydrogen facilitates the $\langle 100\rangle$ binding processes. Thus, the configurations of $\mathrm{V}_{2 \mathrm{Fe}}\langle 110\rangle$ and $\mathrm{V}_{2 \mathrm{Fe}} \mathrm{H}_{12}\langle 100\rangle$ complexes can be a directional unit that forms larger $\mathrm{V}_{2 \mathrm{Fe}}$ and $\mathrm{V}_{2 \mathrm{Fe}} \mathrm{H}_{12}$ clusters.

Upon analyzing the periodic crystal structure of B2-FeAl, we concluded that $\langle 110\rangle$ divacancies are likely to favor not only line clusters along the $\langle 110\rangle$ direction but also tabular ones along the $\{110\}$ or $\{100\}$ planes (Fig. 7). This suggests that there are

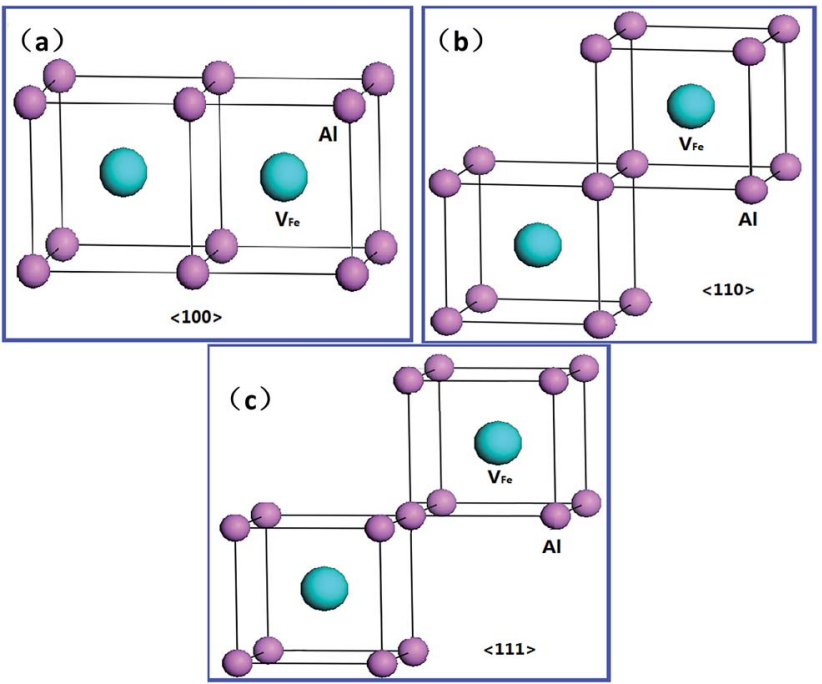

Fig. 6 Schematic views of $\langle 100\rangle$ (a), $\langle 110\rangle$ (b) and $\langle 111\rangle$ (c) Fe divacancies in FeAl.
Table 2 Binding energies $\left(E_{\mathrm{b}}\right)$ of the $\mathrm{V}_{\mathrm{Fe}} \mathrm{H}_{6}$ complexes in FeAl were compared to other computational values. Positive energy indicates that the binding is energetically favorable

\begin{tabular}{llll}
\hline & & & \\
\cline { 3 - 4 } Reactants, $\mathrm{eV}$ & \\
\hline & Products & Our work & Ref. 27 \\
\hline $2 \mathrm{~V}_{\mathrm{Fe}}$ & $\mathrm{V}_{2 \mathrm{Fe}}\langle 111\rangle$ & -0.001 & -0.050 \\
$2 \mathrm{~V}_{\mathrm{Fe}}$ & $\mathrm{V}_{2 \mathrm{Fe}}\langle 110\rangle$ & 0.027 & 0.080 \\
$2 \mathrm{~V}_{\mathrm{Fe}}$ & $\mathrm{V}_{2 \mathrm{Fe}}\langle 100\rangle$ & -0.012 & 0.120 \\
$2 \mathrm{~V}_{\mathrm{Fe}} \mathrm{H}_{6}$ & $\mathrm{~V}_{2 \mathrm{Fe}} \mathrm{H}_{12}\langle 111\rangle$ & 0.000 & - \\
$2 \mathrm{~V}_{\mathrm{Fe}} \mathrm{H}_{6}$ & $\mathrm{~V}_{2 \mathrm{Fe}} \mathrm{H}_{12}\langle 110\rangle$ & 0.002 & - \\
$2 \mathrm{~V}_{\mathrm{Fe}} \mathrm{H}_{6}$ & $\mathrm{~V}_{2 \mathrm{Fe}} \mathrm{H}_{12}\langle 100\rangle$ & 0.051 & - \\
$2 \mathrm{~V}_{\mathrm{Fe}} \mathrm{H}_{6}$ & $\mathrm{~V}_{2 \mathrm{Fe}} \mathrm{H}_{11}\langle 100\rangle+\mathrm{H}_{\text {Oct2Fe-4Al }}$ & 0.048 & - \\
\hline
\end{tabular}

anisotropic $\mathrm{V}_{2 \mathrm{Fe}}$ clusters, whereas $\mathrm{V}_{2 \mathrm{Fe}} \mathrm{H}_{12}\langle 100\rangle$ complexes are likely to favor line clusters along the $\langle 100\rangle$ directions and planar ones along the $\{100\}$ planes. This maintains hydrogen sites as well as the $\langle 100\rangle$ binding networks (Fig. 7) suggesting the presence of isotropic $\mathrm{V}_{2 \mathrm{Fe}} \mathrm{H}_{12}$ clusters.

The $\mathrm{V}_{2 \mathrm{Fe}} \mathrm{H}_{12}\langle 100\rangle$ complex is shown in Fig. 8a. $\mathrm{A}_{2}\langle 100\rangle$ molecule forms inside the complex, and the $\mathrm{H}_{2}$ molecule is located at the Oct site between the two vacancies. The $\mathrm{H}-\mathrm{H}$ bond length is $0.78 \AA$, which is slightly longer than the ideal $\mathrm{H}_{2}$ molecule bond length of $0.74 \AA \AA^{25}$ This is much shorter than the closest distance between hydrogen atoms in the $\mathrm{V}_{\mathrm{Fe}} \mathrm{H}_{6}$ and

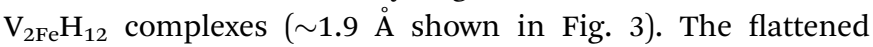
electron clouds of $\mathrm{H}$ atoms in the $\mathrm{V}_{2 \mathrm{Fe}} \mathrm{H}_{12}$ complexes (Fig. 8b) are indicative of $\mathrm{H}-\mathrm{H}$ repulsion. This leads to $\mathrm{H}_{2}$ molecule formation. The $\mathrm{H}_{2}$ bubble nucleation in the Fe atomic divacancy of FeAl is possible in contrast to $\mathrm{H}_{2}$ formation in the monovacancy of pure metal Fe (resulting from the oversaturated hydrogen around the vacancy ${ }^{33}$ ), and that in the $\mathrm{W}$ and Mo are induced by the isosurface of optimal charge density of the vacancy. ${ }^{21}$

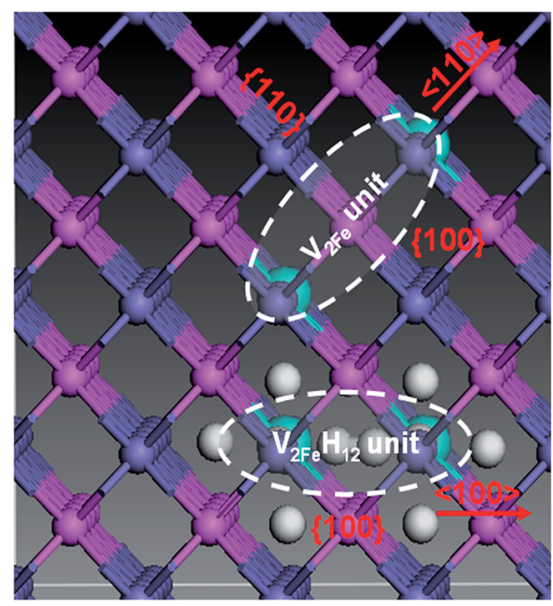

Fig. 7 Probable directions and planes of $\mathrm{V}_{2 \mathrm{Fe}}$ and $\mathrm{V}_{2 \mathrm{Fe}} \mathrm{H}_{12}$ unit clustering. The dashed area denotes $\mathrm{V}_{2 \mathrm{Fe}}$ and $\mathrm{V}_{2 \mathrm{Fe}} \mathrm{H}_{12}$ units, respectively. There are various clusters: line-shaped $\langle 110\rangle$, tabular $\{110\}$, tabular $\{100\} \mathrm{V}_{2 \mathrm{Fe}},\langle 100\rangle$ line-shaped, and tabular $\{100\} \mathrm{V}_{2 \mathrm{Fe}} \mathrm{H}_{12}$. The atoms are placed at the ideal lattice sites, and the atomic relaxations are not shown explicitly. 


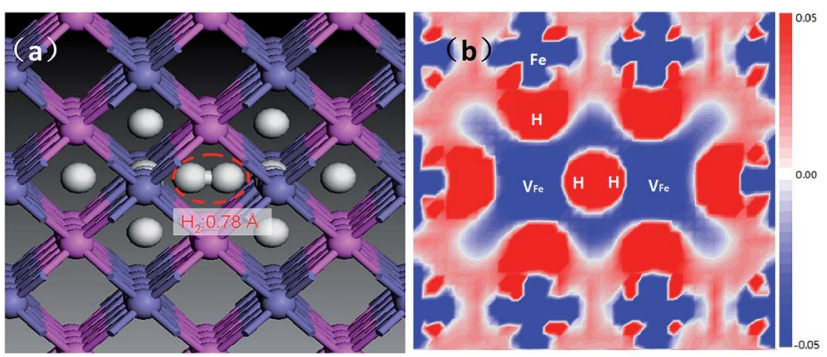

Fig. 8 Local structure of $\mathrm{V}_{2 \mathrm{Fe}} \mathrm{H}_{12}\langle 100\rangle$ cluster-unit. The dashed area denoting the $\mathrm{H}_{2}$ molecule (a), and the corresponding electron density difference is plotted along Fe atoms base (b).

\subsection{How $\mathrm{V}_{\mathrm{Fe}} \mathrm{H}_{n}$ complexes induce hydrogen embrittlement}

These results show the relevance of hydrogenated Fe-vacancy clusters to experimental observed $\mathrm{HE}$ in iron aluminides. For hydrogen-free FeAl, Fe vacancies are difficult to merge due to the high barrier of Fe vacancies (Fig. 9). However, the Fe vacancies binding is preferred along the $\langle 110\rangle$ directions (Table 2), suggesting that the Fe vacancies prefer to grow larger by clusterization of $\mathrm{V}_{2 \mathrm{Fe}}\langle 110\rangle$ units. As shown in Fig. 8, the $\mathrm{V}_{2 \mathrm{Fe}}\langle\mathbf{1 1 0}\rangle$ units are likely to favor not only line shaped clusters along the $\langle 110\rangle$ directions but also tabular ones along the $\{110\}$ or $\{100\}$ planes. Moreover, since $\langle 111\rangle$ are slip directions of bcc metals, the vacancy rows along these directions can be connected with the dislocation motions. ${ }^{30}$ This likely contributes to fracture along the slip planes. These results can be directly linked with several fractures observed in experiments. In a vacuum, fracture has been shown to occur along $\{111\}$ for stoichiometric $\mathrm{Fe}-\mathrm{Al}$ as well as $\{100\}$ for $\mathrm{Fe}-40 \mathrm{Al}$ and $\mathrm{Fe}-35 \mathrm{Al}$.,4

When there is $\mathrm{H}$ in $\mathrm{FeAl}$, the sharply reduced $E^{\mathrm{f}}$ of a $\mathrm{V}_{\mathrm{Fe}}$ near the interstitial $\mathrm{H}$ demonstrates that super-abundant Fe vacancies are easily produced. Meanwhile, $\mathrm{H}$ atoms are easily trapped around the Fe-vacancies at finite temperatures (Fig. 2). Thus, the newly generated Fe-vacancies naturally transform into superabundant $\mathrm{V}_{\mathrm{Fe}} \mathrm{H}_{6}$ complexes. Under such high concentrations, the new $\mathrm{V}_{\mathrm{Fe}} \mathrm{H}_{6}$ complexes do not migrate due to the migration-barrier of $2.89 \mathrm{eV}$ (Fig. 9). The $\mathrm{V}_{\mathrm{Fe}} \mathrm{H}_{6}$ complexes prefer to grow larger by clusterization of $\mathrm{V}_{2 \mathrm{Fe}} \mathrm{H}_{12}\langle 100\rangle$ units, the $\mathrm{V}_{2} \mathrm{FeH}_{12}\langle 100\rangle$ line-shaped clusters, and tabular clusters in $\{100\}$ planes (Fig. 7). These likely contribute to fracture or cracking on

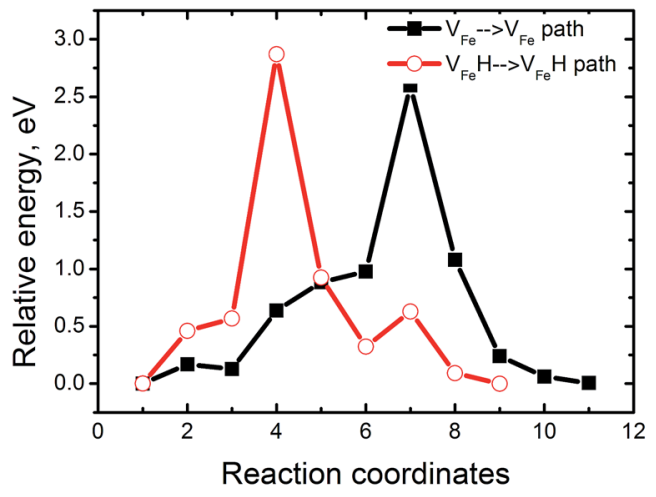

Fig. 9 The energy profiles for $\mathrm{V}_{\mathrm{Fe}}$ and $\mathrm{V}_{\mathrm{Fe}} \mathrm{H}$ diffusion in FeAl. the cleavage planes. Cracking in FeAl propagates mainly along the $\{100\}$ plane in the air, ${ }^{3,4}$ and the edge-oriented $\mathrm{Fe}_{3} \mathrm{Al}$ single crystals show only slight ductility in the air.,

The newly $\mathrm{H}$-induced Fe-vacancies will prefer to grow larger by clusterization of $\mathrm{V}_{2 \mathrm{Fe}}\langle 110\rangle$ units even when $\mathrm{H}$ atoms cannot be trapped by $\mathrm{V}_{\mathrm{Fe}}$ above the finite temperatures or under the condition of low $\mathrm{H}$ concentrations (Fig. 7). Therefore the anisotropic $\mathrm{V}_{2 \mathrm{Fe}}\langle 110\rangle$ clusterization will be enhanced with corresponding fracture and cracking observed in the $\mathrm{H}$-containing FeAl. This is closely consistent with the experimental conclusion that hydrogen charging decreases the intrinsic ductility even more., ${ }^{1,2}$

The data show that hydrogen-induced fracture or cracking through isotropic $\mathrm{V}_{2 \mathrm{Fe}} \mathrm{H}_{12}\langle 100\rangle$ clusters is more relevant to the atomic mechanism of $\mathrm{HE}$ in iron aluminides. In the presence of hydrogen, Fe vacancies in iron aluminides naturally generate into a superabundant concentration and trap $\mathrm{H}$ atoms to form $\mathrm{V}_{\mathrm{Fe}} \mathrm{H}_{6}$ complexes. Because the new $\mathrm{V}_{\mathrm{Fe}} \mathrm{H}_{6}$ complexes prefer to grow larger by clusterization of $\mathrm{V}_{2 \mathrm{Fe}} \mathrm{H}_{12}\langle 100\rangle$ units with $\mathrm{H}_{2}\langle 100\rangle$ molecules, the $\langle 100\rangle$ line-shaped and $\{100\}$ planar clusters can act as the embryos for the formation of cracks and $\mathrm{H}_{2}$ bubbles on the fracture planes. The $\mathrm{H}$ concentrations in FeAl will then increase with FeAl-destroying time extensions. This is because of the high reactivity of the $\mathrm{Al}$ atoms of FeAl with the moisture in air, which creates hydrogen atoms ${ }^{1}$ to facilitate further increases in $\mathrm{V}_{\mathrm{Fe}} \mathrm{H}_{6}$ complexes. As the concentrations of $\mathrm{V}_{\mathrm{Fe}} \mathrm{H}_{6}$ complexes increase, they induce even more $\mathrm{V}_{2 \mathrm{Fe}} \mathrm{H}_{12}\langle 100\rangle$ units, which in turn make the $\langle 100\rangle$ line-shaped and $\{100\}$ planar clusters. The inside $\mathrm{H}_{2}$ bubbles grow even bigger and eventually lead to the macroscopic failure observed experimentally. This is the mechanism of isotropic hydrogenated vacancy clusterinduced HE.

\section{Conclusions}

We investigated $\mathrm{H}$-induced vacancy formation, stability, and clusterization of hydrogen-vacancy complexes $\left(\mathrm{V}_{\mathrm{Fe}} \mathrm{H}_{n}\right)$ in $\mathrm{B} 2-$ FeAl based on DFT calculations and thermodynamic formalism. We identified the contributions of vacancy-related processes to $\mathrm{HE}$ in iron aluminides.

We presented theoretical evidence for the hydrogenenhanced Fe-vacancy formation in FeAl and provide a scenario in which superabundant Fe-vacancies are naturally generated. The $\mathrm{H}$ atoms are more likely trapped around $\mathrm{Fe}-$ vacancies than the diffusion from one octahedral interstitial site to another. One Fe-vacancy can accommodate at most six $\mathrm{H}$ atoms, and the $\mathrm{H}$ atoms occupy six $1 \mathrm{NN}$ Oct $_{2 \mathrm{Fe}-4 \mathrm{Al}}$ sites of the $\mathrm{V}_{\mathrm{Fe}}$ one by one to form $\mathrm{V}_{\mathrm{Fe}} \mathrm{H}_{n}$ complexes. The $\mathrm{H}-\mathrm{H}$ equilibrium distances in the $\mathrm{V}_{\mathrm{Fe}} \mathrm{H}_{n}$ complexes remain on the magnitude of 1.920-2.785 $\AA$, and the $\mathrm{H}-\mathrm{Fe}$ distances range from 1.538 to 1.568 A. The corresponding trapping energies are $0.59-0.66 \mathrm{eV}$ for trapping with 4-6 $\mathrm{H}$ atoms and $0.46-0.53 \mathrm{eV}$ for trapping with 1$3 \mathrm{H}$ atoms, respectively. The competition between metal- $\mathrm{H}$ hybridization and coulombic repulsion makes $\mathrm{V}_{\mathrm{Fe}} \mathrm{H}_{6}$ the major complex under ambient conditions. The $\mathrm{V}_{\mathrm{Fe}} \mathrm{H}_{6}$ complex prefers to grow larger via $\mathrm{V}_{2 \mathrm{Fe}} \mathrm{H}_{12}$ unit clusterization along $\langle 100\rangle$ and $\{100\}$ with internal $\mathrm{H}_{2}$ molecules. This is closely associated 
with the experimental observation of cracking along the $\{100\}$ planes. Thus, a mechanism of isotropic hydrogenated vacancy cluster-induced $\mathrm{HE}$ was proposed to show that isotropic $\mathrm{V}_{2} \mathrm{H}_{12}\langle 100\rangle$ clusters with a linear and planar shape may act as embryos for the formation of cracking, and $\mathrm{H}_{2}$ bubbles. These results offer evidence for the relevance of vacancy-related processes in the atomic-scale mechanism of HE in iron aluminides. This is rarely discussed in the literature.

Of course, our calculations are limited to the study of energetics of hydrogen-vacancy complexes. Kinetic routes for how such complexes evolve to form the cracks will be forthcoming via molecular dynamics and cluster dynamics simulations.

\section{Acknowledgements}

We acknowledge financial supports from the National Natural Science Foundation (No. 21471137, 11275175) and National Magnetic Confinement Fusion Science Program (No. 2013GB110006B, 2014GB110006) of China. The authors also thank the computing resource provided by National Supercomputing Center in Shenzhen.

\section{Notes and references}

1 M. Zamanzade, A. Barnoush and C. Motz, Crystals, 2016, 6, 10.

2 C. Liu, E. Lee and C. McKamey, Scr. Metall. Mater., 1989, 23, 875.

3 M. Nathal and C. Liu, Intermetallics, 1995, 3, 77.

4 R. Lynch, K. Gee and L. Held, Scr. Metall. Mater., 1994, 30, 945.

5 M. Wittmann, D. Wu, I. Baker, E. George and L. Heatherly, Mater. Sci. Eng., A, 2001, 319, 352.

6 H. Saka and T. Ishizaki, Philos. Mag. A, 1996, 73, 173.

7 P. Munroe and I. Baker, Acta Metall. Mater., 1991, 39, 1011.

8 R. Oriani and P. Josephic, Acta Metall., 1979, 27, 997.

9 S. Lynch, Scr. Mater., 2009, 61, 331.

10 P. Ferreira, I. Robertson and H. Birnbaum, Acta Mater., 1999, 47, 2991.

11 J. Yan, C. Wang and S. Wang, Phys. Rev. B: Condens. Matter Mater. Phys., 2005, 72, 134108.

12 H. Li, M. W. Lie, X. Q. Zhang, J. X. Zhang, X. F. Liu and X. F. Bia, J. Phys. Chem. B, 2008, 112, 15588.
13 M. Wang, X. Huang, Z. Du and Y. Li, Chem. Phys. Lett., 2009, 480, 258.

14 G. Zhang, X. Wang, F. Yang, Y. Shi, J. Song and X. Lai, Int. J. Hydrogen Energy, 2013, 38, 7550.

15 J. A. White and D. M. Bird, Phys. Rev. B: Condens. Matter Mater. Phys., 1994, 50, 4954.

16 B. Delley, J. Chem. Phys., 2000, 113, 7756.

17 B. Delley, J. Chem. Phys., 1990, 92, 508.

18 B. Delley, Phys. Rev. B: Condens. Matter Mater. Phys., 2002, 66, 155125.

19 B. Wang, H. Hou, Y. Luo, L. Yan, Y. Zhao and X. Li, J. Phys. Chem. C, 2011, 115, 13399.

20 C. C. Fu and F. Willaime, Phys. Rev. B: Condens. Matter Mater. Phys., 2005, 72, 064117.

21 K. Ohsawa, K. Eguchi, H. Watanabe, M. Yamaguchi and M. Yagi, Phys. Rev. B: Condens. Matter Mater. Phys., 2012, 85, 094102.

22 C. L. Fu and G. S. Painter, J. Mater. Res., 1991, 6, 719.

23 F. J. Donald and A. E. Carter, Acta Mater., 2010, 58, 638.

24 M. Kogachi, T. Haraguchi and S. M. Kin, Intermetallics, 1998, 6, 499.

25 L. E. Sutton, Table of Interatomic Distances and Configuration in Molecules and Ions, 2016, http:/www.webelements.com/ hydrogen/atom_sizes.html.

26 M. Fähnle, J. Mayer and B. Meye, Intermetallics, 1999, 7, 315. 27 R. Besson, A. Legris and J. Morillo, Phys. Rev. B: Condens. Matter Mater. Phys., 2006, 74, 094103.

28 M. Gallouze, A. Kellou, D. Hamoutene, T. Grosdidier and M. Drir, Phys. B, 2013, 416, 1.

29 H. E. Schaefer, K. Frenner and R. Würschum, Phys. Rev. Lett., 1999, 82, 984.

30 Y. Tateyama and T. Ohno, Phys. Rev. B: Condens. Matter Mater. Phys., 2003, 67, 174105.

31 J. Ćížek, F. Lukáč, I. Procházka, M. Vlček, Y. Jirásková, P. Švec and D. Janičkovič, J. Alloys Compd., 2015, 629, 22.

32 G. Lu and E. Kaxiras, Phys. Rev. Lett., 2005, 94, 155501.

33 E. Hayward and C. C. Fu, Phys. Rev. B: Condens. Matter Mater. Phys., 2013, 87, 174103.

34 X. Cheng and X. Wang, Scr. Mater., 1998, 8, 1505.

35 M. Kupka and K. Stepień, Corros. Sci., 2009, 51, 699.

36 K. Ohsawa, J. Goto, M. amakami, M. Yamaguchi and M. Yagi, Phys. Rev. B: Condens. Matter Mater. Phys., 2010, 82, 184117. 